\title{
Asthma control test and pediatric asthma quality of life questionnaire association in children with poor asthma control
}

\author{
Pınar Karadeniz¹, Șebnem Özdoğan ${ }^{1,2}$, Durdugül Ayyıldız-Emecen ${ }^{1}$, Ümmühan Öncül1 \\ Department of Pediatrics ${ }^{1}$, Division of Pulmonology ${ }^{2}$, Şişli Etfal Research and Training Hospital, Istanbul, Turkey. \\ E-mail: Ozdogan65@hotmail.com \\ Received: 10th October 2016, Accepted: 19th December 2016
}

\begin{abstract}
SUMMARY: Karadeniz P, Özdoğan Ş, Ayyıldız-Emecen D, Öncül Ü. Asthma control test and pediatric asthma quality of life questionnaire association in children with poor asthma control. Turk J Pediatr 2016; 58: 464-472.

The aim of this study was to evaluate the association between Pediatric Asthma Quality of Life Questionnaire (PAQLQ) and Asthma Control Test (ACT) in patients with poor asthma control. Children between 7-17 years of age with diagnosis of persistent asthma who are not on daily inhaler corticosteroid therapy were involved. At enrollment, sociodemographic and asthmatic characteristics were investigated and pulmonary function test (PFT), ACT and PAQLQ were administered. Patients were reevaluated following six week regular inhaler therapy and ACT, PAQLQ and PFT were performed. Out of 77 patients, $35(45 \%)$ were female. The mean age was $11.62 \pm 2.35$ years. Following 6 weeks daily inhaler therapy, the scores of ACT, all the parameters of PAQLQ and all the parameters of PFT except FEV1/FVC were significantly increased $(\mathrm{p}<0.05)$. There was a significant correlation between ACT and PAQLQ scores $(\mathrm{r}<0.5, \mathrm{p}=0.001)$. In conclusion, there is a correlation between ACT and PAQLQ.
\end{abstract}

Key words: asthma, children, pediatric asthma quality of life questionnaire, asthma control test.

Asthma is a heterogeneous disorder characterized by chronic inflammation of the airways that is most commonly observed in children. It is identified by respiratory symptoms of varying severity in time including wheezing, dyspnea, chest tightness, coughing, and concomitant expiratory airway obstruction of varying grades ${ }^{1}$.

Well-established international diagnosis, treatment, and monitoring guidelines recommend asthmatic patients be treated and monitored based on asthma control levels. In addition to objective assessments, such as daytime/nighttime symptoms, number of attacks, pulmonary function test (PFT) parameters, the need to use relaxants, agegroup-based asthma control tests (ACTs) have also recently been used because they are rapid and practical $^{2-5}$.

Controlling a patient's asthma with treatment alone does not necessarily mean the patient is healthy, as health is a complete state of wellness of the soul, body, and mind. Health can only be achieved by assessing "quality of life," and improving quality of life is the ultimate objective of healthcare ${ }^{6,7}$. In recent years, tools have been developed and used globally to assess the extent of the effect of asthma on children's quality of life ${ }^{6}$.

In this study, we aimed to evaluate the association of asthma control test (ACT) with pediatric asthma quality of life questionnaire (PAQLQ) before and after 6 weeks of regular inhaler use in children diagnosed with persistent asthma who did not regularly use inhaler treatment.

\section{Material and Methods}

Seventy-seven patients between 7 and 17 years of age, who were under follow-up care at Istanbul Sisli Hamidiye Etfal Training and Research Hospital Pediatric Pulmonary outpatient clinics and diagnosed with persistent asthma as per NAEPP $^{5}$ asthma severity classification but who 
did not use regular inhaler treatment, were included in the study. At initial presentation when patients were enrolled in the study, sociodemographic and asthmatic characteristics were investigated, and PFT, ACT, and PAQLQ were administered. In these patients, an appropriate line of treatment was initiated based on NAEPP and Global Initiative for Asthma GINA) guidelines. Following physical examination performed before and after regular inhaler treatment, PFT, ACT, and PAQLQ were administered. Criteria of exclusion from the study included previous asthma attack within the last 2 weeks, failure to complete the ACT and PAQLQ surveys as required, failure to complete PFT, and loss of follow-up. This study was approved by The Ethics Committee of Istanbul Sisli Hamidiye Etfal Training and Research Hospital. The children and their families also provided informed consent.

Pulmonary Function Test: We used a (MiniSpir ${ }^{\circledR}$ ) calibrated MIR (Medical International Research Srl, Rome, Italy) spirometry device in our study. PFT measurement was conducted in accordance with spirometry application instructions at initial presentation and follow-up. The mean value of the best three PFT runs was calculated.

Asthma Control Tests: Self-reported asthma control test was employed for the assessment of asthma control, the childhood asthma control test (C-ACT) in the case of 7- to 11- year-old children and ACT for children aged 12 years or older2,3. C-ACT is a 7-item asthma control test. The child responds to the survey question using a response scale of $0-3$ points, ranging between a sad face and smiling face. The parent/ person responsible for the child's care assigned a score between 0 and 5 for each question for the last 3 questions. The highest score was 27 and the lowest score was 0. Asthma was considered to be uncontrolled, partly controlled, and controlled for patients with a score $\leq 19$, between 20 and 24 , and $\geq 25$, respectively. The ACT consists of 5 questions and is scored between 1 and 5 points for each question; a total score of 25 indicates that asthma is completely controlled, a score between 10 and 24 indicates partial control, and a score $<20$ indicates lack of control. Both C-ACT and ACT were performed at initial presentation and at follow-up after 6 weeks of regular treatment in this group of patients. Both ACTs were tested for Turkish validity and reliability ${ }^{8,9}$.

PAQLQ: PAQLQ was developed by Juniper et al. ${ }^{10}$ for children between 7 and 17 years of age and has been tested by $\mathrm{H}$ Yuksel et al. ${ }^{11}$ for Turkish reliability and validity. PAQLQ was administered twice to patients face-to-face by the same physician at initial presentation and at follow-up, following 6 weeks of regular inhaler use. Parents were not allowed into the outpatient clinic room during administration of the survey so the children could respond to questions by their own will without being affected by the environment. At the time of first presentation when the patients were enrolled in the study, the patients were asked to pick the 3 activities they found most difficult to perform due to asthma among 39 activities within the last week. The selected activities were recorded on the scale chart to be used in the scale to be administered during follow-up. The children were asked the scale questions at initial presentation and at follow-up, and while answering these questions, they were asked to respond by only assessing their last week. This scale is commonly used worldwide and contains 23 questions and 3 main topics. The questions are classified under three domains:

1) symptoms (questions $4,6,8,10,12,14$, $16,18,20,23$ )

2) activity limitations (questions 1-3, 19, 22)

3 ) emotional functions (questions 5, 7, 9, 11, $13,15,17,21$ )

Four scores, including 3 main topics and 1 total, are obtained from the scale. Each question on the scale is evaluated over 7 points. While 1 indicates excessive discomfort or constant complaining, 7 indicates absence of complaints in relation to scoring. A high score shows a higher quality of life.

Statistical Assessment: IBM SPSS Statistics 22 (IBM SPSS, Turkey) software was used for statistical analyses while assessing the results from the study. The compliance of the parameters to normal distribution was assessed using the Shapiro Wilks test while assessing the study data. In assessing study data, the One Way Anova test for intergroup comparisons of parameters with normal distribution and the Tukey HDS test for detecting the group resulting in the difference 
Table I. Sociodemographic Features of Children and Their Families

\begin{tabular}{|c|c|c|c|c|}
\hline & & & $\mathrm{n}$ & $\%$ \\
\hline & \multicolumn{2}{|c|}{ Age, yr (Min-Max) $($ Mean $\pm S D)$} & $7-17$ & $11.62 \pm 2.35$ \\
\hline & \multirow{2}{*}{ Gender } & female & 35 & 45.5 \\
\hline & & male & 42 & 54.5 \\
\hline & \multirow{3}{*}{ Monthly income $(\mathrm{TL})^{\mathrm{a}}$} & $\leq 1000$ & 32 & 41.6 \\
\hline & & $1000-2000$ & 37 & 48.1 \\
\hline & & $\geq 2000$ & 8 & 10.4 \\
\hline \multirow{6}{*}{ Mother } & \multicolumn{2}{|c|}{ Age, yr (Min-Max) $($ mean $\pm S D)$} & $26-52$ & $37.97 \pm 6.0$ \\
\hline & \multirow{4}{*}{ Educational level } & Illiterate & 11 & 14.3 \\
\hline & & Primary school & 48 & 62.3 \\
\hline & & High school & 16 & 20.8 \\
\hline & & University & 2 & 2.6 \\
\hline & Employed & & 16 & 20.8 \\
\hline \multirow{6}{*}{ Father } & \multicolumn{2}{|c|}{ Age (Min-Max) $($ mean $\pm S D)$} & $29-59$ & $41.91 \pm 5.9$ \\
\hline & \multirow{4}{*}{ Educational level } & Illiterate & 2 & 2.6 \\
\hline & & Primary school & 52 & 67.5 \\
\hline & & High school & 18 & 23.4 \\
\hline & & University & 5 & 6.5 \\
\hline & Employed & & 68 & 88.3 \\
\hline \multirow{8}{*}{ House setting } & \multirow{2}{*}{ Family type } & Extended family & 10 & 13 \\
\hline & & Elementary family & 67 & 87 \\
\hline & \multirow{2}{*}{ Number of family members } & $\leq 4$ & 43 & 55.8 \\
\hline & & $\geq 5$ & 34 & 44.2 \\
\hline & & none & 34 & 44.2 \\
\hline & \multirow[t]{2}{*}{ Smoking } & 1 member & 29 & 37.7 \\
\hline & & $\geq 2$ members & 14 & 18.2 \\
\hline & Pet at home & & 8 & 10.4 \\
\hline \multicolumn{2}{|c|}{ Family history of asthma } & & 27 & 35.1 \\
\hline \multicolumn{2}{|l|}{ Total IgE } & high & 42 & 54.5 \\
\hline \multicolumn{2}{|c|}{ Specific inhaled allergen } & high & 48 & 62.3 \\
\hline
\end{tabular}

aTurkish Lira $(\mathrm{TL})=0.310$ Euro

was used to compare quantitative data as well as descriptive statistical methods (mean, standard, deviation, frequency). Student $t$ test was used to compare the parameters with normal distribution between the two groups. A paired sample $t$-test was used for intragroup comparisons of the parameters. As for comparison of the qualitative data, chi-square test, Fisher's Exact Chi-Square test, and Continuity (Yates) Correction was used. The correlations among ACT and PAQLQ scores were determined by using Pearson's test. The significance was set at $\mathrm{p}<0.05$.

\section{Results}

The sociodemographic features of the patients included in the study and their parents are presented in Table I. The study was performed with 77 cases total, including 35 females (45.5\%) and 42 males (54.5\%). The patients' ages ranged between 7 and 17 years, with a mean age of $11.62 \pm 2.35$ years. While $41.6 \%$ of the cases had a monthly income $\leq 1,000$ $\mathrm{TL}, 48.1 \%$ had a monthly income between 1,000 and $2,000 \mathrm{TL}$ and $10.4 \%$ had an income $\geq 2,000 \mathrm{TL}$ ( $\mathrm{TL}=0.310$ Euro). The mean age of the mothers was $37.97 \pm 6.02$ years. Reviewing 
Table II. Distribution of ACT Results at Presentation and After 6 Weeks of Inhaler Therapy (FollowUp) by the Status of Control

\begin{tabular}{lcc}
\hline \multirow{2}{*}{ *ACT } & & Total \\
\cline { 3 - 3 } & & $\mathrm{n}(\%)$ \\
\hline \multirow{2}{*}{ Presentation } & Partly controlled & $6 \quad(\% 7.8)$ \\
& Uncontrolled & $71(\% 92.2)$ \\
\multirow{2}{*}{ Follow-up } & Controlled & $9 \quad(\% 11.7)$ \\
& Partly controlled & $48 \quad(\% 62.3)$ \\
& Uncontrolled & $20 \quad(\% 26)$ \\
\hline
\end{tabular}

*ACT: asthma control test

Fisher's Exact Test and Chi-square Test

the level of education, $14.3 \%(n=11)$ were illiterate, $62.3 \%(n=48)$ were primary school graduates, $20.8 \%(n=16)$ were high-school graduates and $2.6 \%$ were university graduates. $20.8 \%(n=16)$ of the mothers were employed. The mean age of the fathers was $41.91 \pm 5.91$ years. While $2.6 \%(n=2)$ of the fathers were illiterate, $67.5 \%(n=52)$ were primary school graduates, $23.4 \%(n=18)$ were high school graduates and $6.5 \%(n=5)$ were university graduates. $88.3 \%(n=68)$ of the fathers were employed. $87 \%(n=67)$ of the cases were in an elementary family, while $44.2 \% \quad(n=34)$ were in a family with $\geq 5$ members. While $44.2 \%(\mathrm{n}=34)$ did not have any smoking family members, $55.8 \%(\mathrm{n}=43)$ had $\geq 1$ smoking family member. $10.45(\mathrm{n}=8)$ of the cases had pets. $35.1 \%(n=27)$ of the cases had family history of asthma. While $54.5 \%(n=42)$ had a total IgE that was high by age, $62.3 \%(n=48)$ were reported to have a high specific inhaled allergen level.

ACT assessments before and after regular inhaler treatment are presented in Table II. While $92.2 \%(n=71)$ of the patients had uncontrolled asthma before treatment, $26 \%$ $(n=20)$ still had uncontrolled asthma following regular inhaler treatment. The mean scores for ACT, PFT, and PAQLQ at initial presentation and after 6 weeks of regular inhaler treatment are presented in Table III. A statistically significant increase was detected in all PFT parameters except the FEV1/FVC ratio, the ACT score, and the PAQLQ scores after 6 weeks of regular inhaler treatment $(p=0.001)$.

The correlation between ACT and PAQLQ scores before and after regular treatment and the change in score was investigated (Table IV). A correlation was detected between pre and post treatment ACT and PAQLQ 3 subunit and
PAQLQ total scores $(\mathrm{r}=0.385-0.584, \mathrm{p}=0.001)$. There was also a correlation between posttreatment ACT score change and PAQLQ 3 subunit and total score change $(r=0.360-0.489$, $\mathrm{p}=0.001$ ).

The association between the change in PAQLQ scores and sociodemographic features are presented in Table V. A significant correlation was detected for total PAQLQ score changes in patients with a family consisting of $\geq 5$ members $(p=0.037)$. There was a significant correlation between the mean increase in PAQLQ total and 3 subunit scores, and the presence of pets in the house $(p=0.026,0.008$, 0.018 , and 0.006 , respectively). A significant correlation was detected between high specific inhaled allergen level, activity score, emotional function score change, and total score change except PAQLQ symptoms score $(\mathrm{p}=0.034$, 0.005 , and 0.009). No statistically significant correlation was detected between the other sociodemographic features and the PAQLQ scores $(p>0.05)$.

\section{Discussion}

Asthma is the most common chronic lowerrespiratory-tract disease of childhood and has physical, emotional, and social effects on life. Although asthma has a low mortality rate, it is of high importance with respect to morbidity and chronicity. Current treatment guidelines recommend using asthma control levels for treatment follow-up ${ }^{4,5}$. If an asthmatic child experiences concentration impairment with a difference in disease perception or has social loss, complete recovery cannot be considered even if the asthma control level has been improved because health is a complete state of wellness of the soul, body, and mind. Patients benefit from asthma treatment not 
Table III. The Mean Scores for ACT, PFT and PAQLQ at Initial Presentation and After 6 Weeks of Inhaler Treatment (Follow-Up)

\begin{tabular}{|c|c|c|c|c|}
\hline & & & mean $\pm S D$ & $\mathrm{p}$ \\
\hline \multirow[t]{6}{*}{ ACT } & & Presentation & $14.38 \pm 3.60$ & $0 \cap 0 \cap 1 * *$ \\
\hline & & Follow-up & $21.05 \pm 3.13$ & 0.001 \\
\hline & \multirow{2}{*}{ FVC } & Presentation & $2.9 \pm 0.77$ & $0.001^{* *}$ \\
\hline & & Follow-up & $3.04 \pm 0.81$ & \\
\hline & \multirow{2}{*}{$\% \mathrm{FVC}$} & Presentation & $101.64 \pm 13.24$ & $0.001^{* *}$ \\
\hline & & Follow-up & $106.44 \pm 13.02$ & \\
\hline \multirow{6}{*}{ PFT } & \multirow{2}{*}{ FEV1 } & Presentation & $2.45 \pm 0.71$ & $0.001^{* *}$ \\
\hline & & Follow-up & $2.6 \pm 0.72$ & \\
\hline & \multirow{2}{*}{$\%$ FEV1 } & Presentation & $98.48 \pm 15.59$ & $0.001^{* *}$ \\
\hline & & Follow-up & $103.58 \pm 14.38$ & \\
\hline & \multirow{2}{*}{ FEV1/ FVC } & Presentation & $0.84 \pm 0.08$ & 0.155 \\
\hline & & Follow-up & $0.85 \pm 0.07$ & \\
\hline \multirow{8}{*}{ PAQLQ scores } & \multirow{2}{*}{ Symptoms score } & Presentation & $37.05 \pm 11.7$ & $0.001^{* *}$ \\
\hline & & Follow-up & $56.61 \pm 11.6$ & \\
\hline & \multirow{2}{*}{ Activity limitation } & Presentation & $18.14 \pm 5.04$ & $0.001^{* *}$ \\
\hline & & Follow-up & $26.51 \pm 5.23$ & \\
\hline & \multirow{2}{*}{$\begin{array}{l}\text { Emotional functions } \\
\text { score }\end{array}$} & Presentation & $39.08 \pm 11.01$ & $0.001^{* *}$ \\
\hline & & Follow-up & $48.92 \pm 8.28$ & \\
\hline & \multirow{2}{*}{ Total score } & Presentation & $94.27 \pm 24.45$ & $0.001^{* *}$ \\
\hline & & Follow-up & $132.04 \pm 22.68$ & \\
\hline
\end{tabular}

ACT: asthma control test PFT: pulmonary function test PAQLQ: pediatric asthma quality of life questionnaire Paired Sample t Test ${ }^{* *} \mathrm{p}<0.01$

Table IV. The Correlation Between ACT and PAQLQ Scores Before and After Regular Treatment (Follow Up) and the Change in Score

\begin{tabular}{|c|c|c|c|c|}
\hline & & & \multicolumn{2}{|c|}{ ACT } \\
\hline & & & $\mathrm{r}$ & $\mathrm{p}$ \\
\hline \multirow{12}{*}{ PAQLQ score } & \multirow{3}{*}{ Symptoms score } & Presentation & 0.526 & $0.001^{* *}$ \\
\hline & & Follow-up & 0.565 & $0.001^{* *}$ \\
\hline & & Change in score & 0.489 & $0.001^{* *}$ \\
\hline & \multirow{3}{*}{ Activity limitation } & Presentation & 0.385 & $0.001^{* *}$ \\
\hline & & Follow-up & 0.550 & $0.001^{* *}$ \\
\hline & & Change in score & 0.378 & $0.001^{* *}$ \\
\hline & \multirow{3}{*}{$\begin{array}{l}\text { Emotional } \\
\text { functions score }\end{array}$} & Presentation & 0.455 & $0.001^{* *}$ \\
\hline & & Follow-up & 0.461 & $0.001^{* *}$ \\
\hline & & Change in score & 0.360 & $0.001^{* *}$ \\
\hline & \multirow{3}{*}{ Total score } & Presentation & 0.536 & $0.001^{* *}$ \\
\hline & & Follow-up & 0.584 & $0.001^{* *}$ \\
\hline & & Change in score & 0.486 & $0.001^{* *}$ \\
\hline
\end{tabular}

ACT: asthma control test PAQLQ: pediatric asthma quality of life questionnaire Pearson correlation analysis ${ }^{*} \mathrm{p}<0.05 \quad{ }^{* *} \mathrm{p}<0.01$ 
Table V. The Association Between the Change in PAQLQ Scores and Sociodemographic Features

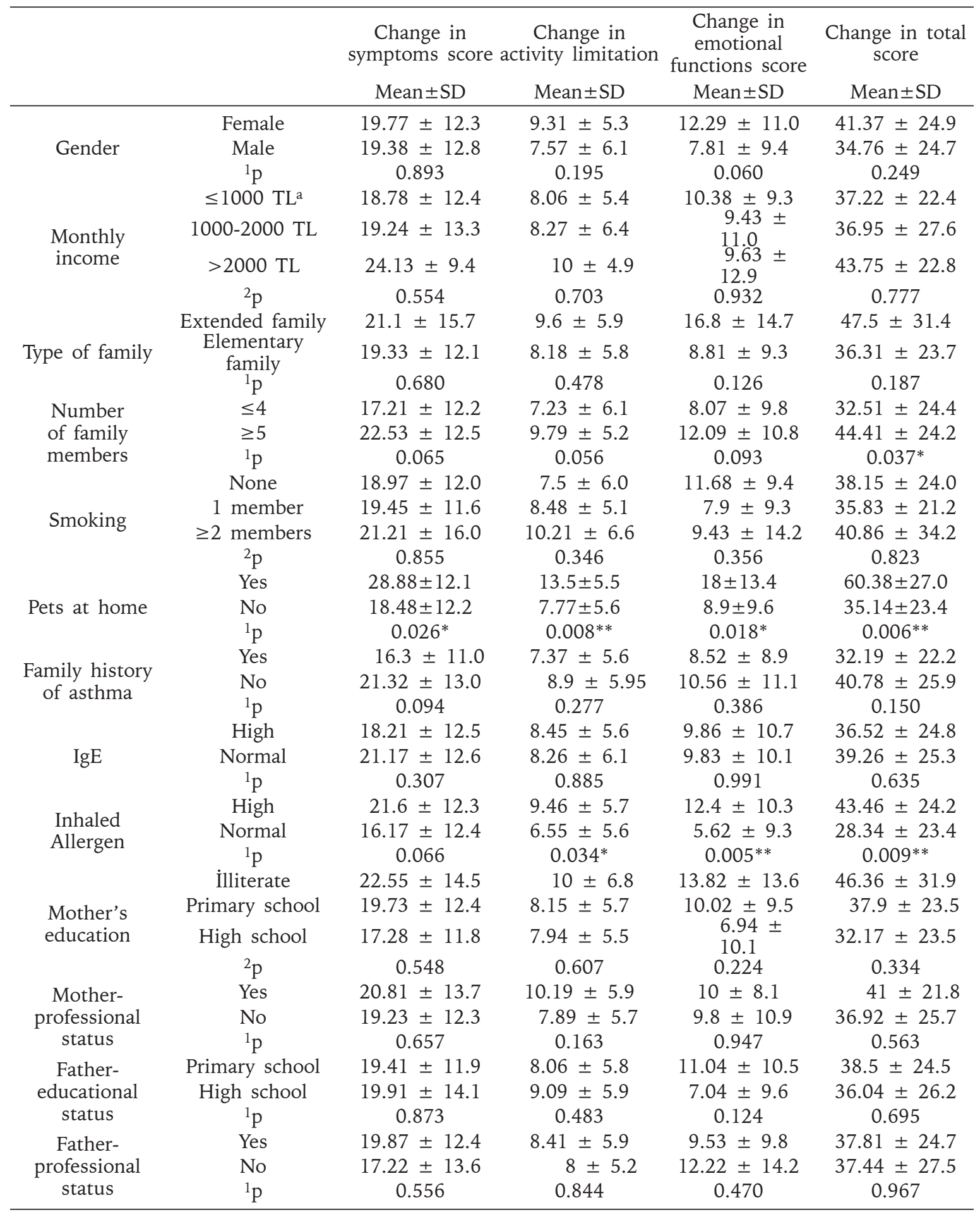

PAQLQ: pediatric asthma quality of life questionnaire

aTL: 0.310 Euro ${ }^{1}$ Student $t$ Test ${ }^{2}$ One-Way ANOVA test ${ }^{*} \mathrm{p}<0.05{ }^{* *} \mathrm{p}<0.01$

only in physical terms but also in social and emotional respects. Health-related quality-oflife surveys should be used in assessing this ${ }^{10}$.
A large number of studies demonstrate that asthma control provides a better quality of life, thereby leading to a reduction in physical and 
emotional variability in social relations , $^{6,12-15}$. In our study, asthma control, ACT scores, PAQLQ scores, and all PFT parameters, except the FEV1/FVC ratio, were significantly increased following 6 weeks of regular inhaler treatment. Of the PFT parameters, FEV1 and FVC increased similarly; thus, the FEV1/FVC ratio did not increase. A statistically strong correlation is detected between pre-treatment and post-treatment ACT and PAQLQ scores. We believe that the improvement in asthma control achieved by appropriate regular treatment is favorably reflected in patients' quality of life. There are many studies in the literature that report a strong correlation between ACT and PAQLQ ${ }^{16-18}$.

In a study by Ramirez et al. ${ }^{19}$ quality of life was found to be better in asthmatic children in a regular asthma program who used regular treatment. In another study, PAQLQ score was detected to be significantly lower in asthmatic children compared to healthy controls. In the same study, patients with asthma diagnosis were observed to have a very low PAQLQ score. It was concluded that an asthma diagnosis was enough for a patient to perceive quality of life as low even if the patient's asthma was under control. A similar contradiction was also observed in the study by Juniper et $\mathrm{al}^{21}$.

In our study, reviewing the association between sociodemographic features and the PAQLQ score differences, PAQLQ score was detected to be significantly increased with treatment in patients with $\geq 5$ family members. This suggests that as the number of family members increases, the social network also increases and, thus, the patient's quality of life improves. In contrast to the opinion that a crowded family is associated with poor life conditions, the presence and supply of the family is important for the patient to address these life changes, as is the case in other chronic diseases. In a study performed in children, pediatric patients with more than one sibling were detected to have a higher 3 domain score and total PAQLQ score ${ }^{11}$.

In our study, we detected a significant increase in all PAQLQ scores following treatment in patients with pets at home. We believe that the emotional connection established between children and pets favorably impacts the quality of life. Although removing pets from the houses of children sensitive to pet allergens is reportedly very effective at controlling allergic symptoms, the same cannot be said for improving asthmatic symptoms or reducing sensitivity ${ }^{22}$. The relationship between the pet and the owner is always emotional; therefore, before investigating the presence of allergens based on suspicion and taking relevant measures, a test needs to be performed to establish the presence of the allergen. An association between pet feeding and asthma cannot be clearly elucidated ${ }^{23}$.

In our study, we observed a significant increase in the total PAQLQ score and in the sub-scores of the activity limitation score and emotional function score, but not the symptoms score, in cases with a high level of specific inhaler allergens following treatment. This suggests that patients with a high specific inhaled allergen level have a more severe course of asthma due to their atopic nature and have a more marked improvement in their quality of life as they respond more dramatically to regular inhaler treatment. However, there are many studies in the literature that report that a history of atopy does not affect the patient's quality of life ${ }^{16,24,25}$.

There is no association between the type of family, educational or professional status of the parents, asthma history in the family, monthly income, exposure to smoking, and high IgE level and changes in the PAQLQ score. Although there are studies suggesting the presence of an association between the mother's educational and professional status, family's monthly income, and PAQLQ scores, the association to passive smoking is contradictive ${ }^{26-28}$.

The limitation of our study is that our sample may not reflect global asthmatic children. Additionally, because patients were administered the ACT and PAQLQ surveys for the second time at follow-up, they may have responded the questions in a biased manner. This study was conducted in children from low soscioeconomic levels. The factors such as education of patients and parents, and monthly income should be considered in order to improve the follow up and treatment of these children.

In conclusion, there is a statistically significant correlation between pre-treatment and posttreatment ACT and PAQLQ scores. Patients benefit from asthma treatment not only 
physically but also socially and emotionally; to assess these benefits, health-related qualityof-life surveys should be used. Quality-of-life surveys represent a bridge in perceiving the difference between the child's personal concerns about asthma and the asthma control level. Therefore, we need to use quality-of-life scales more in regular treatment and follow-up of chronic diseases such as asthma.

\section{Acknowledgements}

The authors thank all of the children and their families who participate in this study for their valuable contribution.

\section{REFERENCES}

1. Reddel HK, Bateman ED, Becker A, et al. A summary of the new GINA strategy: a roadmap to asthma control. Eur Respir J 2015; 46: 622-639.

2. Liu AH, Zeiger R, Sorkness C, et al. Development and cross-sectional validation of the Childhood Asthma Control Test. J Allergy Clin Immunol 2007; 119: 817825.

3. Thomas M, Kay S, Pike J, et al. The Asthma Control Test (ACT) as a predictor of GINA guideline-defined asthma control: analysis of a multinational crosssectional survey. Prim Care Respir J 2009; 18: 41-49

4. Global Initiative for Asthma . Global strategy for asthma management and prevention. Updated 2015. http://www.ginasthma.org/local/uploads/files/GINA Report_2015.pdf. Access date: 20th July 2015.

5. National Asthma Education and Prevention Program: Expert panel report III: Guidelines for the diagnosis and management of asthma. Bethesda, MD: National Heart, Lung and Blood Institute, 2007. (NIH publication no. 08-4051). www.nhlbi.nih.gov/guidelines/asthma/ asthgdln.htm (Accessed on May 21, 2015).

6. Juniper EF. Effect of asthma on quality of life. Can Respir J. 1998; 5(Suppl A): 77A-84A.

7. Annett RD. Assessment of health status and quality of life outcomes for children with asthma. J Allergy Clin Immunol 2001; 107: S473-S481.

8. Sekerel BE, Soyer OU, Keskin O, et al. The reliability and validity of Turkish version of Childhood Asthma Control Test. Qual Life Res 2012; 21: 685-690.

9. Uysal MA, Mungan D, Yorgancioglu A, et al. Turkish Asthma Control Test (TACT) Study Group. The validation of the Turkish version of Asthma Control Test. Qual Life Res 2013; 22: 1773-1779.

10. Juniper EF, Guyatt GH, Feeny DH, Ferrie PJ, Griffith LE, Townsend M. Measuring quality of life in children with asthma. Qual Life Res 1996; 5: 35-46.

11. Yüksel H, Yilmaz O, Kirmaz C, Eser E. Validity and reliability of the Turkish translation of the Pediatric Asthma Quality of Life Questionnaire. Turk J Pediatr 2009; 51: 154-160.
12. Gandhi PK, Kenzik KM, Thompson LA, et al. Exploring factors influencing asthma control and asthma-specific health-related quality of life among children. Respir Res 2013; 14: 26.

13. Schmier JK, Manjunath R, Halpern MT, Jones ML, Thompson K, Diette GB. The impact of inadequately controlled asthma in urban children on quality of life and productivity. Ann Allergy Asthma Immunol 2007; 98: 245-251.

14. Welch MJ, Carlson AM, Larson D, Fena P. Clinical profile, health-related quality of life, and asthma control in children attending US asthma camps. Ann Allergy Asthma Immunol 2007; 99: 496-501.

15. Dean BB, Calimlim BM, Kindermann SL, Khandker RK, Tinkelman D. The impact of uncontrolled asthma on absenteeism and health-related quality of life. J Asthma 2009; 46: 861-866.

16. Nordlund B, Konradsen JR, Pedroletti C, Kull I, Hedlin G. The clinical benefit of evaluating health-related quality-of-life in children with problematic severe asthma. Acta Paediatr 2011; 100: 1454-1460.

17. Matsunaga NY, Ribeiro MA, Saad IA, Morcillo AM, Ribeiro JD, Toro AA. Evaluation of quality of life according to asthma control and asthma severity in children and adolescents. J Bras Pneumol 2015; 41: 502-508.

18. Amaral LM, Moratelli L, Palma PV, Leite IC. The quality of life of Brazilian adolescents with asthma: associated clinical and sociodemographic factors. J Asthma 2014; 51: 660-666.

19. Ramírez Narváez C, González Moro P, del Castillo Gómez L, García Cos JL, Lahoz Rallo B, Barros Rubio C. Quality of life in a population of asthmatic children. Aten Primaria 2006; 38: 96-101.

20. van Gent R, van Essen LE, Rovers MM, Kimpen JL, van der Ent CK, de Meer G. Quality of life in children with undiagnosed and diagnosed asthma. Eur J Pediatr 2007; 166: 843-848.

21. Juniper EF, Wisniewski ME, Cox FM, Emmett AH, Nielsen KE, O’Byrne PM. Relationship between quality of life and clinical status in asthma: a factor analysis. Eur Respir J 2004; 23: 287-291.

22. Rao D, Phipatanakul W. Impact of environmental controls on childhood asthma. Curr Allergy Asthma Rep 2011; 11: 414-420.

23. Apfelbacher C, Frew E, Xiang A, Apfel A, Smith $\mathrm{H}$. Assessment of pet exposure by self-report in epidemiological studies of allergy and asthma: a systematic review. J Asthma 2016: 53: 363-373.

24. Coban H, Aydemir Y. The relationship between allergy and asthma control, quality of life, and emotional status in patients with asthma: a cross-sectional study. Allergy Asthma Clin Immunol 2014; 10: 67.

25. Ponte EV, Souza-Machado A, Souza-Machado C, Franco $\mathrm{R}$, Cruz AA. Atopy is not associated with poor control of asthma. J Asthma 2012; 49: 1021-1026. 
26. Al-Gewely MS, El-Hosseiny M, Elezz Abou NF, ElGhoneimy DH, Hassan AM. Health-related quality of life in childhood bronchial asthma. Egypt J Pediatr Allergy Immunol 2013; 11: 83-93.

27. Olson LM, Lara M, Frintner MP. Measuring health status and quality of life for US children: Relationships to race, ethnicity and income status. Ambul Pediatr 2004; 4: 377-386.
28. Taminskiene V, Mukhopadhyay S, Palmer C, et al Factors associated with quality of life in children with asthma living in Scotland. Pediatr Pulmonol 2016; 51: 484-490. 